\title{
EVALUASI SISTEM PENGELOLAAN LIMBAH CAIR DI RUMAH SAKIT PARU SURABAYA
}

\author{
Elis Sugihartini, Ferry Kriswandana, Hadi Suryono
}

\begin{abstract}
Hospital activities could be potentially reduces the quality of the environment and public health, especially from the medical home activities. One of this activity produces liquid waste that are harmful to the hospital environment and the surrounding community if the disposal is not treated before discharge into the water streams, thus it is important to monitoring and handling in the hospital environment.

This research is a descriptive study with the aim to describe the existing condition of the Waste Management System on Pulmonary Hospital at Surabaya. This research is useful to the Hospital in order to improve their tunnel and immediately running the IPAL to reduce the levels of pollutants and becomes the safe environment.

The results of this study showed that the effluent liquid waste on Pulmonary Hospital at Surabaya has not been in compliance with the State Environmental Ministerial Decree of Republic Indonesia No : MEP - 58/MENLH/XIII/1995 because in the results of laboratory examinations was conducted on May 11, 2013 as the parameters of BOD, COD, TSS, and MPN, the coli bacteria/100 obtain a percentage of $134 \mathrm{ml} \mathrm{mg} / \mathrm{l}, 237 \mathrm{mg} / \mathrm{l}, 20 \mathrm{mg} / \mathrm{l}$ and $9 \times 10^{-8}$ MPN/100 ml which is not considered feasible due to exceeding quality standards for liquid waste Constanta to be dispose in water streams. Problems that exist in pulmonary hospitals nowadays is the liquid waste treatment system due to discharge of liquid waste generated from various sources is not running yet and it does not meet the capacity of the existing IPAL, irregularities found in the existing management system in a pulmonary hospital Surabaya, after investigators traced by researchers there are some pipelines that leak or loss of liquid waste that directly flows in drainage tunnels, and the sump apparently are not water resistant, and it caused the water seep or seep into the ground.

It is advisable for the pulmonary hospital at Surabaya to improve the liquid waste systems, from the source to the hospitals liquid waste treatment such as repairing tunnels and fixing the sump. And the most important thing is to immediately run the existing IPAL in pulmonary hospital Surabaya so that the disposal of liquid waste can be reducing the levels of pollutants and does not pollute or adversely affects the hospital environment or the local community.
\end{abstract}

\section{Keywords $\quad$ : Liquid waste management systems, hospital liquid waste, Hospital liquid waste impacts.}

\section{PENDAHULUAN \\ Latar Belakang}

Dalam meningkatkan kesehatan masyarakat, sebagai penunjang kesejahteraan masyarakat banyak, rumah sakit menjadi salah satu tempat dalam mendukung kesehatan dan kesejahteraan masyarakat. Selain membawa dampak positif bagi masyarakat, yaitu sebagai tempat menyembuhkan orang sakit, rumah sakit juga memiliki kemungkinan membawa dampak negatif. Dampak negatifnya dapat berupa pencemaran lingkungan atau penyakit pada manusia seperti penyakit diare, disentri dan muntaber yang dapat membahayakan bagi masyarakat sekitar dari suatu proses kegiatan, yaitu bila limbah yang dihasilkan tidak dikelola dengan baik.

Kegiatan di Rumah Sakit dapat berpotensi menurunkan kualitas lingkungan dan kesehatan masyarakat, terutama dari aktivitas rumah medis. Aktivitas ini menghasilkan buangan limbah cair yang berbahaya bagi masyarakat sekitar apabila pembuangannya tanpa diolah sebelum di buang pada badan air. Sehingga penting dilakukan penanganan dan pemantauan lingkungan di Rumah Sakit. 
Rumah Sakit Paru Surabaya yang berlokasi di Jl. Karang Tembok No. 39, Kelurahan Pegirian Kecamatan Semampir Kota Surabaya merupakan rumah sakit tipe $\mathrm{C}$ yang mempunyai tempat tidur sebanyak 57 tempat tidur. Berdasarkan data eksisting dari Rumah Sakit Paru Surabaya didapat bahwa debit air yang masuk di instalasi pengolahan limbah cair belum memenuhi kapasitas IPAL yang ada di Rumah Sakit Paru Surabaya yang seharusnya sebanyak $120 \mathrm{~m}^{3} /$ harinya. Dari data Rekap kunjungan Rawat Inap RS Paru Surabaya diperoleh keterangan bahwa dari rata - rata BOR (bed ouccupancy rate) per bulannya dengan jumlah tempat tidur yang ditempati pasien sebanyak 28 tempat tidur (bed) dengan manghasilkan buangan limbah cair sebanyak $14 \mathrm{~m}^{3} /$ hari, hal tersebut mengakibatkan belum beroperasinya instalasi pengolahan limbah cair secara optimal di Rumah Sakit Paru Surabaya.

\section{Tujuan}

Mengetahui sistem pengelolaan limbah cair pada Rumah Sakit Paru di Karang Tembok No 39 Kota Surabaya Tahun 2013.

\section{Metode Penelitian}

Jenis penelitian ini merupakan penelitian cross sectional dan lokasi penelitian dilakukan di Rumah Sakit Paru Surabaya, Jl. Karang Tembok No. 39 Surabaya. Dilakukan pada bulan Mei - Juni, variabel terikat dari penelitian ini adalah Sumber limbah cair, Karakteristik limbah cair, Kapasitas/debit buangan limbah cair, Sistem penyaluran limbah cair, Instalasi pengolahan limbah cair, dan Kualitas efluen limbah cair meliputi $\mathrm{BOD}_{5}, \mathrm{COD}, \mathrm{TSS}$, dan MPN-kuman Golongan koli dan untuk data yang telah terkumpul disusun dan dikelompokkan kemudian di interprestasikan hasil pemantauannya dengan cara memberikan rekomendasi untuk peningkatan sistem pengelolaan di Rumah Sakit Paru Surabaya.

\section{Hasil Penelitian dan Pembahasan}

\section{Sumber - Sumber Limbah Cair Di Rumah Sakit Paru Surabaya}

Terdapat 14 sumber penghasil limbah cair dirumah sakit Paru Surabaya diantaranya adalah rawat jalan, ruang UGD, Rawat Inap, ruang bersalin, ruang oprasi, ruang ICU, ruang KIA, laboratorium, ruang radiologi, ruang farmasi, kantor, laundry, dapur dan mushola. Pada setiap masing masing sumber limbah cair Rumah Sakit Paru Surabaya sudah ada pipa penyalur yang dibuat dan disesuaikan dengan fungsi serta tujuan penggunaan yaitu untuk menyalurkan limbah cair agar sampai pada bak pengumpul dan bak penampung, namun untuk saluran yang berasal dari dapur perlu diberi grease trap atau penengkap lemak agar tidak terjadi penyumbatan akibat dari sisa - sisa makanan.

\section{Karakteristik Limbah Cair Rumah Sakit Paru Surabaya}

Dari pengamatan secara langsung yang dilakaukan di Rumah Sakit Paru Surabaya dari kondisi eksisting bahwa buangan limbah cair Rumah Sakit Paru Surabaya memiliki karakteristik sebagai berikut :

Tabel 1

Jenis Karakteristik Limbah Cair

Yang Dihasilkan Rumah Sakit Paru Surabaya

Tahun 2013

\begin{tabular}{|c|c|c|c|}
\hline NO. & PARAMETER & SATUAN & KADAR \\
\hline 1. & Fisika & ${ }^{0} \mathrm{C}$ & 28 \\
\hline 2. & $\begin{array}{l}\text { BOD } \\
\text { COD } \\
\text { TSS }\end{array}$ & $\mathrm{mg} / \mathrm{liter}$ & $\begin{array}{c}134 \\
237 \\
20\end{array}$ \\
\hline 3. & $\begin{array}{l}\text { Mikrobiologi } \\
\text { MPN-kuman } \\
\text { golongan koli/100 ml }\end{array}$ & $\mathrm{MPN} / 100 \mathrm{ml}$ & $9 \times 10^{8}$ \\
\hline
\end{tabular}


Sifat dari limbah cair Rumah Sakit Paru Surabaya adalah termasuk limbah cair dengan sifat lemah karena volume suspensi pada (suspended solid) kurang dari 100 $\mathrm{mg} / \mathrm{l}$. Untuk karakteristik limbah cair adalah secara kimia untuk parameter pemeriksaan BOD dengan kadar $134 \mathrm{mg} / \mathrm{l}$ dan untuk parameter COD dengan kadar $237 \mathrm{mg} / \mathrm{l}$, sedangkan pada pengukuran dengan karakteristik bakteriologis untuk parameter MPN kuman golongan koli dengan kadar sebesar $9 \times 10^{8} \mathrm{MPN} / 100 \mathrm{ml}$. Untuk standart baku mutu limbah cair bagi kegiatan rumah sakit dengan parametar BOD adalah kadar maksimum $30 \mathrm{mg} / \mathrm{l}$, COD kadar maksimum $80 \mathrm{mg} / \mathrm{l}$ dan MPN kuman golongan koli kadar maksimum $10.000 \mathrm{MPN} / 100 \mathrm{ml}$, sehingga dapat disimpulkan kandungan yang terdapat pada limbah cair melebihi standart baku mutu limbah cair bagi kegiatan rumah sakit menurut KepMen Negara Lingkungan Hidup RI No:MEP58/MENLH/XII/1995.

\section{Debit Limbah Cair Rumah Sakit Paru Surabaya}

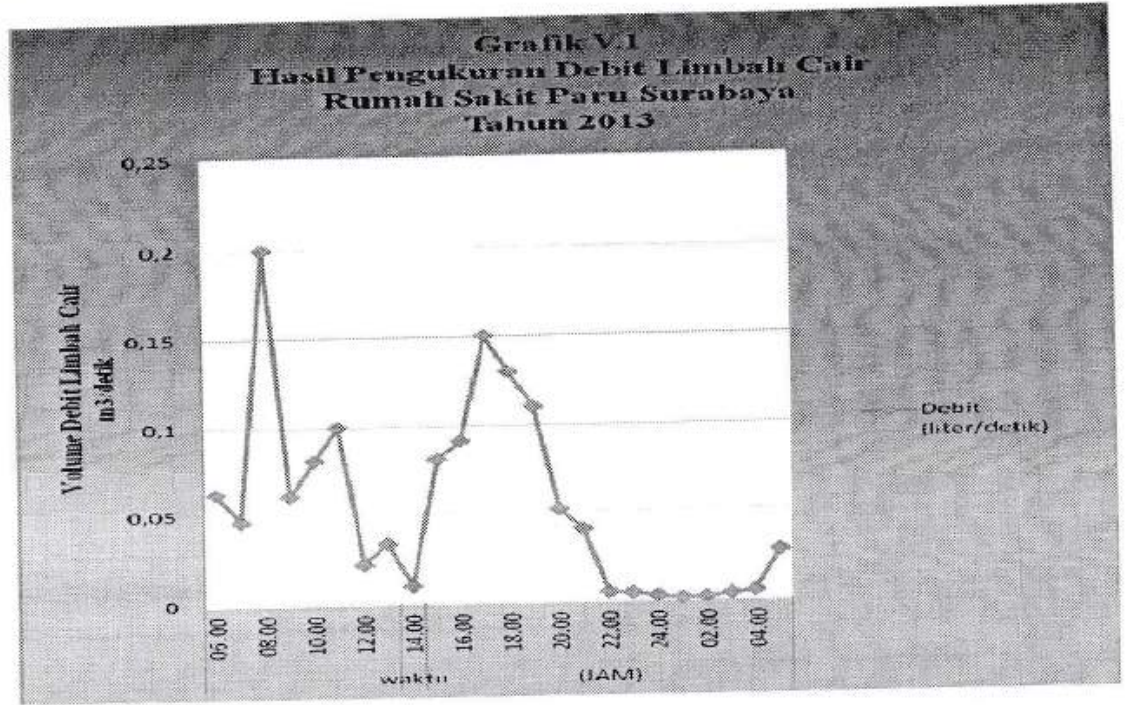

Seperti pada gambar grafik diatas menunjukkan bahwa hasil buangan limbah cair yang paling banyak terjadi pada pukul 08.00 am dengan menghasilakan volume sebesar 0,2 liter/detik dikarenakan pada waktu tersebut sedang terjadi proses pencucian/ laundry yang dilakukan oleh petugas rumah sakit untuk pakaian dan sprei dari kamar - kamar pasien. Dari hasil pengukuran secara langsung, yang dilakukan peneliti maka pengukuran yang sudah diketahui adalah untuk debit buangan limbah cair Rumah Sakit Paru Surabaya memperoleh debit minimum dengan volume sebesar 0,0015 liter/detik dan debit maksimum dengan volume sebesar 0,2 liter/detik maka volume rata rata yang diperoleh sebesar 0,055 liter/detik atau $0,198 \mathrm{~m}^{3} / \mathrm{jam}$ dan 4,752 $\mathrm{m}^{3} /$ hari.
Sistem Penyaluran Limbah Cair Rumah Sakit Paru Surabaya

Sistem penyaluran limbah cair yang digunakan oleh Rumah Sakit Paru Surabaya adalah dengan menggunakan sistem perpipaan tertutup dengan memanfaatkan sistem yang menggunakan pemompaan tekanan untuk mengalirkan limbah cair menuju ke Instalasi Pengolahan Limbah Cair (IPAL). Pipa yang digunakan adalah PVC type AW dengan diameter sebagai berikut :

$$
\begin{array}{llll}
\text { Pipa Induk } & : & 8^{\prime \prime} & \varnothing \\
\text { Pipa Transmisi } & : & 3^{\prime \prime} & \varnothing
\end{array}
$$

Instalasi Pengolahan Limbah Cair Rumah Sakit Paru Surabaya

Pada sistem pengolahan limbah cair Rumah Sakit Paru Surabaya menggunakan sistem BIOCAPS TANK yang mempunyai tahapan untuk menurunkan kadar polutan yang ada 
pada buangan limbah cair diantaranya adalah Tangki Ekualisasi (Balance Tank), Proses Netralisasi, Tangki Aerasi, Bak sedimentasi dan Bak Klorinasi, sudah bisa dibilang dapat menurunkan kadar pencemar yang dihasilkan dari buangan limbah cair Rumah Sakit Paru Surabaya apabila proses berjalan dengan optimal. Hal ini ditunjukkan dengan sudah banyaknya pemakaian BIOCAPS yang digunakan oleh rumah sakit lain untuk menangani buangan limbah cair dan menurunkan kadar pencemar yang ada pada limbah cair rumah sakit.

\section{Analisa Hasil Buangan Limbah Cair Rumah Sakit Paru Surabaya}

Untuk melihat cemaran limbah cair yang dihasilkan oleh Rumah Sakit Paru Surabaya sebelum dilakukan pengolahan limbah cair maka dilakukan pengukuran dengan parameter pencemar limbah cair untuk rumah sakit diantaranya adalah $\mathrm{BOD}, \mathrm{COD}$, TSS dan MPN-kuman golongan Koli.

Tabel 2

Hasil Pengukuran Parameter Limbah Cair

Di Rumah Sakit Paru Surabaya Tahun 2013

\begin{tabular}{|c|c|c|c|c|}
\hline No. & PARAMETER & SATUAN & KADAR & $\begin{array}{c}\text { KADAR } \\
\text { MAKSIMUM }\end{array}$ \\
\hline 1. & Fisika & ${ }^{\circ} \mathrm{C}$ & 28 & $\leq 30$ \\
\hline 2. & $\begin{array}{l}\text { BOD } \\
\text { COD } \\
\text { TSS } \\
\end{array}$ & $\mathrm{mg} /$ liter & $\begin{array}{c}134 \\
237 \\
20 \\
\end{array}$ & $\begin{array}{l}30 \\
80 \\
30 \\
\end{array}$ \\
\hline 3. & $\begin{array}{l}\text { Mikrobilogi } \\
\text { MPN-kuman golongan } \\
\text { koli/100 ml }\end{array}$ & MPN/100 ml & $9 \times 10^{8}$ & 10.000 \\
\hline
\end{tabular}

Pada hasil pengukuran sampel yang dilakukan pada pipa outlet atau penampung sementara untuk saluran limbah cair dengan menggunakan perameter pencemar $B O D, C O D$, TSS dan MPN-kuman golongan koli sebagai parameter pencemar limbah cair dengan kadar sebagai berikut, untuk BOD sebesar $134 \mathrm{mg} / \mathrm{L}$, COD sebesar 237 $\mathrm{mg} / \mathrm{L}$, TSS sebesar $20 \mathrm{mg} / \mathrm{L}$ dan MPNkuman golongan koli sebesar $9 \times 10^{8}$ MPN/100ml tergolong tidak layak karena melebihi baku mutu limbah cair dengan standart baku mutu bagi kegiatan rumah sakit untuk parameter BOD, COD, TSS, dan MPN kuman golongan koli adalah sebesar $30 \mathrm{mg} / \mathrm{l}, 80 \mathrm{mg} / \mathrm{l}, 30 \mathrm{mg} / \mathrm{l}$ dan 10.000 MPN/100ml dalam peraturan KepMEn Negara Lingkungan hidup RI No : MEP 58/MENLH/XIII/1995 untuk langsung dibuang pada badan air. Maka prose IPAL yang ada di Rumah Sakit Paru Surabaya harus segera berjalan untuk menurunkan kadar pencemar yang ada pada limbah cair sehimgga tidak menimbulkan pencemaran bagi lingkungan rumah sakit dan masyarakat sekitar.

\section{Kesimpulan dan saran Kesimpulan}

1. Limbah cair yang dihasilkan dari aktivitas Rumah Sakit Paru Surabaya dari tiap sumber - sumber diantaranya adalah rawat Jalan, UGD, rawat Inap, ruang Bersalin, ruang oprasi, ICU, ruang KIA, Laboratorium, ruang radiologi, ruang farmasi, kantor, laundry dan dapur untuk penyaluran buangan limbah cair bisa berjalan sesuai fungsi dan sebagaimana mestinya namun terdapat beberapa kebocoran dan penyumbatan pada saluran perpipaan yang membuat air tidak bisa mengalir secara keseluruhan atau hilang dan mengalir langsung pada selokan sekitar rumah 
sakit dan pada penangan laundry dan dapur terdapat grease trap untuk mengakap lemak.

2. Sifat dan karakteristik limbah cair Rumah Sakit Paru Surabaya untuk pemeriksaan sampel menyatakan bahwa sifat limbah cair lemah dengan karakteristik kimia untuk parameter BOD dan COD dan bakteriologis untuk parameter MPN kuman Golongan koli.

3. Dari hasil pengukuran debit buangan limbah cair rumah sakit, maka diperoleh hasil debit buangan limbah cair dengan hasil rata - rata sebesar 0,055 liter/detik atau $0,198 \mathrm{~m}^{3} / \mathrm{jam}$ atau $4,752 \mathrm{~m}^{3} /$ hari.

4. Pada sistem penyaluran limbah cair di Rumah Sakit Paru Surabaya yaitu menggunakan sistem gravitasi dan menggunakan sistem pemompaan bertekanan untuk mengalirkan limbah cair menuju ke Instalasi Pengolahan Limbah Cair (IPAL).

5. Pada instalasi pengolahan limbah cair di Rumah Sakit Paru Surabaya menggunakan Biocaps yang mempunyai tahapat - tahapan untuk pengolahan limbah cair agar bisa sesuai baku mutu limbah cair Rumah Sakit dan tidak mencemari lingkungan sekitar, namun untuk saat ini proses IPAL sendiri belum berjalan dikarenakan masih belum terpenuhinya buangan limbah cair yang dihasilkan karena terdapat saluran perpipaan yang bocor dan terdapat konstruksi bangunan yang tidak kedap air.

6. Hasil pengukuran sampel yang dilakukan pada tanggal 13 Mei 2013 pada outlet atau penampung sementara, keadaan limbah cair yang ada di rumah sakit paru surabaya belum mencapai batas kadar maksimum baku mutu limbah cair bagi kegiatan rumah sakit yang diatur pada KepMen Negara Lingkungan Hidup RI No :MEP- 58/MENLH/12/1995.

\section{SARAN}

1. Bagi dinas Kesehatan :

Sebaiknya dilakukan pemantauan kualitas limbah cair di Rumah Sakit Paru Surabaya untuk melakukan audit atau pemeriksaan sesuai dengan KepMen Negara Lingkungan Hidup RI No: MEP-58/MENLH/12/1995 dengan parameter suhu, $\mathrm{pH}, \mathrm{BOD}, \mathrm{COD}$, TSS, dan MPN kuman golongan koli.
2. Bagi Pihak Rumah Sakit Paru Surabaya :

a. Seharusnya proses IPAL segera dijalankan untuk menurunkan kadar pencemar yang ada pada buangan limbah cair agar tidak mencemari lingkungan rumah sakit dan masyarakat sekitar.

b. Sebaiknya pada saluran perpipaan perlu dilakukan pengecekan atau pengontrolan untuk setiap sumber penghasil buangan limbah cair yang dihasilkan setiap harinya agar tidak terjadi penyumbatan atau kebocoran pada saluran perpipaan dan proses penyaluran bisa berjalan lancar menuju IPAL, kemudian bisa dilakukan pengolahan agar sesuai baku mutu limbah cair rumah sakit.

c. Sebaiknya terdapat alat ukur debit buangan limbah cair agar mempermudah petugas dalam mengecek atau mengontrol buangan limbah cair yang dihasilkan tiap harinya.

d. Sebaiknya pada bak - bak pengumpul diberi tutup yang bisa dibuka atau ditutup agar bisa dilakukan pengecekan apabila terjadi penyumbatan saluran oleh kotoran.

e. Sebaiknya pada bak - bak penampung dibuat agar bangunan kedap air sehingga limbah cair yang sudah tertampung tidak merembes kedalam tanah.

f. Sebaiknya pada bak - bak pengumpul dibuat kedap air agar limbah cair yang sudah mengumpul jadi satu tidak meresap kedalam tanah dan bisa langsung diteruskan pada IPAL rumah sakit kemudian dilakukan pengolahan limbah cair agar sesuai baku mutu limbah cair rumah sakit yang terdapat pada peraturan KepMen Negara Lingkungan Hidup RI No: MEP58/MENLH/12/1995.

g. Apabila dalam penggunaan proses IPAL sekarang membutuhkan biaya yang besar karena penambahan blower untuk suplai oksigen, sebagai alternatif lain sebaiknya menggunakan pengolahan limbah cair dengan proses biologis yang memanfaatkan aktivitas mikroorganisme secara an-aerobik (tanpa bantuan oksigen) yang lebih efisien dari faktor biaya dan sistem oprasionalnya. 


\section{DAFTAR PUSTAKA}

Ardianto, Wiku. 2008. Audit Lingkungan Rumah Sakit. Jakarta,

Buku BP4/ Rumah Sakit Paru Surabaya, tahun 2010

Djabu, Udin dkk. 1990/1991. Pedoman Bidang Studi Pembuangan Tinja dan Air Limbah Pada Institusi Pendidikan Sanitasil Kesehatan Lingkungan. Jakarta, Pusat Pendidikan Tenaga Kesehatam DepKes RI.

Keputusan Gubernur Kepala Daerah Tingkat I Jawa Timur Nomor 40 dan 41 Tahun 1996 Tentang Baku Cara Pengambilan Contoh Air dan Limbah Cair Di Propinsi Daerah Tingkat I Jawa Timur dan Baku Cara Uji Air Limbah Dan Limbah Cair Di Propinsi Daerah Tingkat I Jawa Timur.

Keputusan Gubernur Kepala Daerah Tingkat I Jawa Timur Nomor 6

Tahun 1991 tentang Baku Mutu Limbah Cair Bagi kegiatan Rumah Sakit di Propinsi Daerah tingkat 1 Jawa Timur.
Keputusan Menteri Kesehatan Republik Indonesia Nomor 1204 tahun 2004 Tentang Persyaratan Kesehatan Rumah Sakit.

Keputusan Menteri Negara Lingkungan Hidup RI Nomor 58 tahun 1995 Tentang Baku Mutu Limbah Cair Bagi Rumah sakit.

Kurniadie, Denny. 2011. Teknologi Pengolahan Limbah Cair Secara Biologis.

Merdeka Wati, Tri Habsari.2005. Pengembangan Protap Pengelolaan Limbah Cair Rumah Sakit Guna meningkatkan Kualitas Limbah Cair Rumah Sakit, (Studi Kasus Pengelolaan Limbah Cair di Badan Pelayanan RSU Wangaya Kota Denpasar). Program Paska Sarjana Universitas Airlangga.

Purwanto, Didik Sugeng. 2008. Pengelolaan Limbah Cair. Surabaya, Teori Praktis Tenaga Sanitasi.

Soeparman, Soeparmin. 2001. Pembuangan Tinja dan Limbah Cair. Jakarta, Buku Kedokteran. 